V Seminário Anual Científico e Tecnológico | Bio-Manguinhos

\title{
GES 05 - Ferramenta de criticidade para o processo decisório da gestão de manutenção de equipamentos de controle de qualidade no caso Alfaepoetina.
}

Aline da Silva Lima ${ }^{*}$; Cristine Maria de Lima Andrade ; André Ribeiro de Oliveira ${ }^{2}$; Aline de Araújo Pereira ${ }^{\mathbf{1}}$, Nathalia Ferreira Valentim da Silva ${ }^{\mathbf{1}}$.

1 Bio-Manguinhos / Fiocruz;

2 UERJ.

\section{Introdução:}

O conjunto de equipamentos analíticos de controle de qualidade para atender a produção de produtos terapêuticos e biológicos líquidos injetáveis, como a Alfaepoetina, necessita de uma Engenharia de Manutenção proativa e eficiente. As atividades fundamentadas em testes físico-químicos, biológicos e microbiológicos, dependem, dentre outros recursos, da disponibilidade dos equipamentos analíticos intermediados com as melhores práticas de gestão, relacionados diretamente à gestão de manutenção e à gestão de riscos operacionais, prevendo a indisponibilidade de equipamentos e promovendo a melhoria do desempenho para atender ao fornecimento dos produtos ao SUS.

\section{Objetivo:}

Aplicar metodologia para análise de criticidade e operacionais dos equipamentos do processo de controle de qualidade da Alfaepoetina. Melhorar o desempenho dos tempos de liberação de produtos com as melhores práticas na gestão de equipamentos, desde a visão de processos do Controle de Qualidade pela Engenharia de Manutenção.

\section{Metodologia:}

Verificaram-se os macroprocessos do Departamento de Qualidade ANDRADE (2011), o Certificado de Liberação do produto e as Instruções de trabalho relacionadas à Alfaepoetina. Realizaram-se entrevistas com responsáveis dos processos, identificaramse os equipamentos utilizados e mantidos pelo Departamento de Manutenção, categorizando a criticidade pelo critérios de MACEDO, (2011): velocidade de manifestação da falha, segurança do pessoal e do ambiente, custos de parada de produção, custos de reparação, documentação, origem, gargalo, mão de obra e idade do equipamento. Os dados foram alinhados para o plano de manutenção e operacionais da 
área. Definiram-se graus de importância para os critérios utilizando a matriz de decisão de Mudge, para definir a classificação de criticidade alta, média e baixa.

\section{Resultado:}

Para a rota dos testes de liberação e atividades de apoio de controle de qualidade de Alfaepoetina, composto por quinze equipamentos de dez instruções de trabalho em doze processos relacionados, classificamos os equipamentos. $70 \%$ foram classificados com criticidade média, $18 \%$ com criticidade alta e 12\% com criticidade baixa. Foi elaborado o plano de manutenção contemplando diretrizes de atuação para cada nível de criticidade de equipamentos, tais como: peça de reposição dos itens de equipamentos mais críticos em estoque, estruturação do corpo de manutenção para eficácia no atendimento, políticas de contrato de outsourcing de manutenção, critérios para back up de equipamentos, etc.

\section{Conclusão:}

A ferramenta desenvolvida contribui para o alinhamento da missão de Bio -Manguinhos ao atendimento ao SUS, já que facilita e dá suporte às decisões estratégicas no processo decisório entre VQUAL - Vice Diretoria de Qualidade e VGEST - Vice Diretoria de Gestão, quanto à gestão de recursos financeiros e demandas de fornecimento de produtos estratégicos aos clientes PNI, MS entre outros, pois o método pode ser replicado em novas rotas de produtos. Ao nível estratégico o desdobramento deste estudo realizado, auxilia no planejamento dos recursos, para cada caso quanto à alocação de investimentos no parque tecnológico.

\section{Palavras-chave: Política de Manutenção; Macroprocessos; Qualidade}

